\title{
Green tea extract and epigallocatechin 3-gallate reduced labile iron pool and protected oxidative stress in iron-loaded cultured hepatocytes
}

\author{
Somdet Srichairatanakool ${ }^{1}$, Kanokwan Kulprachakarn ${ }^{1}$, Kanjana Pangjit ${ }^{1,2}$, Kovit Pattanapanyasat ${ }^{3}$, \\ Suthat Fuchaeron ${ }^{*}$ \\ ${ }^{1}$ Department of Biochemistry, Faculty of Medicine, Chiang Mai University, Chiang Mai, Thailand \\ ${ }^{2}$ College of Medicine and Public Health, Ubon Ratchathani University, Ubon Ratchathani, Thailand \\ ${ }^{3}$ Office of Research and Development, Faculty of Medicine Siriraj Hospital, Mahidol University, Bangkok, Thailand \\ ${ }^{4}$ Thalassemia Research Center, Institute of Molecular Bioscience, Mahidol University Salaya Campus, Nakornpathom, Thailand \\ Email: "grsfc@mahidol.ac.th
}

Received 10 September 2012; revised 16 October 2012; accepted 19 November 2012

\begin{abstract}
Cellular and mitochondrial damage can be caused by labile iron pool (LIP) and mediated by reactive oxygen species (ROS). Livers of the thalassemias have highly increased levels of LIP and ROS. Green tea extract (GTE) and epigallocatechin 3-gallatte (EGCG) can potentially protect liver inflammation, fibrosis and cancer due to their anti-oxidative and iron-chelating activities. We studied the effects of GTE and EGCG on intracellular LIP and ROS, and mitochondrial membrane potential $\left(\Delta \Psi_{m}\right)$ in mouse hepatocyte and HepG2 cell cultures using specific fluorescent techniques. Treatment with GTE $(12.5-25 \mathrm{mg} / \mathrm{dl})$ and EGCG (25 - $50 \mu \mathrm{M})$ significantly lowered levels of $\Delta \Psi_{\mathrm{m}}$ in the mouse hepatocytes; however, combined treatment of $25 \mu \mathrm{M}$ DFP with GTE and EGCG did not enhance the decrease of hepatic $\Delta \Psi_{\mathrm{m}}$. The results showed that GTE and EGCG effectively removed the intracellular LIP and ROS, and relieved the mitochondria membrane collapse of the liver cells, suggesting a hepatoprotective effect of green tea extract and EGCG in the hepatocytes with iron overload. Their actions might be related to iron-chelating and free radical-scavenging capacities. Whether the effects can improve iron overload and oxidative stress in thalassemia patients remains to be seen upon further examination.
\end{abstract}

Keywords: Green Tea; Epigallocatechin Gallate; Hepatocytes; Labile Iron Pool; Iron; Reactive Oxygen Species

\section{INTRODUCTION}

Excess iron catalyzes production of reactive oxygen spe-

${ }^{*}$ Corresponding author. cies (ROS) via Fenton/Haber-Weiss reaction [1], which in turn induces the oxidation of proteins, lipids and lipoproteins, nucleic acids, carbohydrates [2,3]. Accordingly, the deleterious effects result in cell and organelle damage, cell death, tissue necrosis, and organ dysfunction. bThalassemia patients suffer from secondary iron overload and therefore require effective iron chelation with desferrioxamine (DFO), deferiprone (DFP) and deferasirox (DFX). Iron could also function as a priming or sensitizing factor to modulate the biochemical and toxicological actions of microsomal cytochrome P450 2E1 (CYP2E1) in rat hepatocytes and HepG2 cells [4]. In postulate intracellular labile iron pool (LIP) would be redox-active, chelatable low-molecular-mass iron $\left(\mathrm{Fe}^{2+}\right.$ rather than $\mathrm{Fe}^{3+}$ ). A wide range of LIP concentrations have been reported in erythroid and myeloid cells [5], peripheral blood lymphocytes [6], mouse lymphoma cells [7] and rat hepatocytes, as well as subcellular organelles [8]. Importantly, the LIP plays a role in the induction of cellular and tissue oxidative damage. In the liver with iron overload and oxidative stress, free radicals and their lipid-peroxidation products can trigger organelle dysfunctions, inflammation, fibrosis and eventually cell death [9]. Reduction of the LIP with iron chelators or/and antioxidants prevents nuclear and mitochondrial DNA breaks of the liver cells. An association of CYP2E1-dependent oxidative stress, mitochondrial membrane-potential $\left(\Delta \Psi_{\mathrm{m}}\right)$ collapse and GSH depletion possibly contributes toward the developing toxicity of iron to the liver [10].

Green tea (Camellia sinensis) contains catechin derivatives including gallic acid (GA), epigallocatechin (EGC), epicatechin (EC), epigallocatechin 3-gallate (EGCG) and epicatechin 3-gallate (ECG), of which EGCG is a major active ingredient [11,12]. EGC, EGCG, ECG and EC exhibited binding activity to iron with a molar ratio of $3: 2,2: 1,2: 1$ and 3:1, respectively [13]. Their iron- 
binding activity influenced a change of iron-induced calcium homeostasis in liver tissue suspension [14]. Interestingly, EGCG protected CYP2E1-dependent oxidative stress and iron toxicity in HepG2 cells [15] and inhibited iron-induced lipid peroxidation in rat liver microsomes [16], possibly by iron-chelating and free-radical scavenging properties. A previous study reported that green tea catechins counteracted oxidative mitochondrial damage in the livers of reserpine-treated rats [17]. However, the order of cytotoxicity of the tea catechins to rat heaptocytes has been reported: EGCG > ECG > GA, EGC > EC [18]. A combination of chloroform extract from Zizyphus jujube and green tea enhanced the inhibition of HepG2 cell growth [19].

Our studies have shown that green tea extract (GTE) ameliorated iron overload and oxidative stress in rats [20] and inhibited the accumulation of iron in the livers of wild-type and thalassemic mice [21]. Circumstantial data reported a biological evaluation of combined chelation therapy for reducing iron overload [22-25]. Hypothetically, DFP could induce its iron to shuttle with green tea catechins to enhance the reduction of iron overload and oxidative stress. In this study, we examined effects of the GTE and EGCG on levels of LIP, ROS and $\Delta \Psi_{\mathrm{m}}$ in primary hepatocyte and HepG2 cell cultures. Combined treatments of DFP with GTE and EGCG were also investigated.

\section{MATERIALS AND METHODS}

\subsection{Chemicals}

Acetonitrile, absolute ethanol, ethyl acetate, and methanol were the highest pure solvents. Calcein-AM solution (Invitrogen Corporation, CA, USA), dihydrorhodamine 123 (DHR123) (Biotium, Inc., CA, USA), and 2',7'dichlorodihydrofluorescein diacetate (DCFHDA) (SigmaAldrich, St. Louis, MO, USA) were the fluorescent probes. Collagenase type IV, Dulbecco's modified eagle medium (DMEM), Kreb-Ringer buffer (KRB), penicillin-streptomycin, $0.5 \%$ trypsin-EDTA solution and fetal bovine serum were purchased from GIBCO $^{\circledR}$ Invitrogen, CA, USA. Insulin (Humulin ${ }^{\mathbb{R}} \mathrm{R}$ ) is a prodcut of Health Central Network Inc., USA. Dexamethazone, dihydrogen phosphate potassium salt $\left(\mathrm{KH}_{2} \mathrm{PO}_{4}\right)$, disodium hydrogen phosphate $\left(\mathrm{Na}_{2} \mathrm{HPO}_{4}\right)$, 4-(2-hydroxyethyl)-1-piperazine ethane sulfonic acid (HEPES), 3-(4,5-dimethyl thiazol2-yl)-2,5-diphenyl tetrazolium bromide (MTT dye), ethylene glycol-bis(2-amino ethyl ether)-N,N,N',N'-tetraacetic acid (EGTA), hydrogen peroxide (30\%), and EGCG were obtained from Sigma-Aldrich, St Louis, MO, USA. Dimethyl sulfoxide (DMSO) (Fisher Scientific, UK), ferric ammonium citrate (FAC) (BDH, England) and DFO (Novatis, Switzerland) were purchased from a dug store in Maharaj Nakorn Chiang Mai Hospital, Faculty of
Medicine, Chiang Mai University. Deferiprone (DFP) was kindly donated by Dr. Chada Phisalapong, Government Pharmaceutical Organization Thailand.

\subsection{Green Tea and EGCG Preparations}

Fresh tea shoots were harvested and immediately dried in a microwave oven $\left(3 \mathrm{~min}, 800\right.$ watts, $\left.100^{\circ} \mathrm{C}\right)$. Dry tea leaves were extracted with hot deionized water $\left(80^{\circ} \mathrm{C}\right)$ for $15 \mathrm{~min}$ and filtered through $0.45-\mu \mathrm{m}$ membrane (cellulose acetate type, Millipore, Maidstone, England) and dried under a vacuum. Results of HPLC analysis using the column (Waters SpheroSorb-ODS2, $250 \mathrm{~mm} \times 4.7$ $\mathrm{mm}, 5-\mu \mathrm{m})$, mobile-phase solvent $\left(0.05 \% \mathrm{H}_{2} \mathrm{SO}_{4}\right.$ :acetonitrile:ethyl acetate $=86: 12: 2, \mathrm{v} / \mathrm{v} / \mathrm{v}$ ), a flow rate of 1.0 $\mathrm{ml} / \mathrm{min}$, as well as the detection of $280 \mathrm{~nm}$, indicated amounts of EGC, C, EC, EGCG, ECG and total catechin quantities persisting in the GTE were 102, 5.1, 53.9, 88.7, 4.3 and $255 \mathrm{mg} / \mathrm{g}$ dry weight, respectively $[11,12,21]$. EGCG was isolated from green tea extract $(5.0 \%, \mathrm{w} / \mathrm{v})$ using semi-preparative HPLC according to the following conditions: the main column (Luna ODS2, $250 \mathrm{~mm} \times 10$ $\mathrm{mm}, 5 \mu \mathrm{m}$, Phenomenex ${ }^{\circledR}$, Torrance, California, USA) connected to the guard column (Luna ODS2, $50 \times 10 \mathrm{~mm}$, $5 \mu \mathrm{m}$, Phenomenex ${ }^{\circledR}$, Torrance, California, USA), isocratic elution with solvent (methanol: $\mathrm{H}_{2} \mathrm{O}=29: 71, \mathrm{v} / \mathrm{v}$ ) at a flow rate of $1.0 \mathrm{ml} / \mathrm{min}$, and detection of catechin derivatives at $280 \mathrm{~nm}$. EGCG fraction was pooled and checked for purity using the analytical HPLC as described above. Methanol constituted in the pooled fractions was removed under a vacuum using a freeze-dry technique. Prior to being used, lyophilized EGCG fraction was stored in the dark at $-20^{\circ} \mathrm{C}$.

\subsection{Isolation and Cultures of Hepatocytes}

Mice (C57/BL6, age 9 - 12 wk, weight 30 - 35 g) were provided by Professor Suthat Fucharoen at Thalassemia Research Center, Institute of Molecular Biosciences, Mahidol University and used as a source of primary heaptocytes. The animal study was conducted with the approval of the Institutional Animal Care and Use Committee (IACUC) of the Faculty of Medicine, Chiang Mai University (Reference Number-3/2548). Mice were anesthetized with vapor diethyl ether and their chests were opened. The liver was perfused in situ via the portal vein with the Kreb-Ringer buffer (KRB), pH 7.4 comprising $116 \mathrm{mM} \mathrm{NaCl}, 5.4 \mathrm{mM} \mathrm{KCI}, 25 \mathrm{mM} \mathrm{NaHCO}_{3}$ and 0.63 $\mathrm{mM}$ EGTA at $37^{\circ} \mathrm{C}$ at a flow rate of $1 \mathrm{ml} / \mathrm{min}$ for 20 minutes and with the KRB buffer containing $1 \mathrm{mM} \mathrm{CaCl}_{2}$, $0.025 \%(\mathrm{w} / \mathrm{v})$ collagenase type IV for $20 \mathrm{~min}$. The livers were excised, teased apart, incubated at $37^{\circ} \mathrm{C}$ for a further $15 \mathrm{~min}$ in the collagenase solution, and isolated hepatocytes were harvested through nylon mesh (250 $61 \mu \mathrm{m})$. Crude cells were sedimented by differential cen- 
trifugation $(60 \mathrm{~g})$ for $5 \mathrm{~min}$ at $25^{\circ} \mathrm{C}$ and resuspended in the $20 \mathrm{mM}$ HEPES buffer containing $116 \mathrm{mM} \mathrm{NaC} 1,5.4$ $\mathrm{mM} \mathrm{KCI}, 1 \mathrm{mM} \mathrm{CaCl}_{2}, \mathrm{pH}$ 7.4. Cell viability was assayed using trypan blue exclusion technique. Cell numbers were adjusted to $4 \times 10^{5}$ viable cells $/ \mathrm{ml}$ and cultured in DMEM supplemented with $10 \%$ (v/v) FBS, $2.0 \mathrm{mM}$ glutamine, $100 \mathrm{U} / \mathrm{ml}$ penicillin $/ 100 \mathrm{U} / \mathrm{ml}$ streptomycin, $200 \mathrm{~m} \mathrm{U} / \mathrm{ml}$ insulin and $1 \mu \mathrm{M}$ dexamethasone. Human hepatoma (HepG2) cells were used to study the biochemical and toxicological properties due to their increased oxidative stress, loss of mitochondrial function, and loss of viability when challenged with proxidants such as iron [26]. Cells were cultured in complete DMEM containing $2 \mathrm{mM}$ glutamine, pyridoxine hydrochloride, $110 \mathrm{mg} / 1$ sodium pyruvate, $10 \mathrm{mM}$ HEPES, $44 \mathrm{mM}$ $\mathrm{NaHCO}_{3}, 10 \%(\mathrm{v} / \mathrm{v})$ inactivated FBS and $0.01 \%(\mathrm{w} / \mathrm{v})$ penicillin-streptomycin $37^{\circ} \mathrm{C}$ [27].

\subsection{Chelation of LIP of Hepatocyte Cultures}

Primary hepatocytes and HepG2 cells $\left(5 \times 10^{3}\right.$ cells/well $)$ were exposed to FAC solution $(0.5 \mathrm{mM})$ at $37^{\circ} \mathrm{C}$ under $5 \% \mathrm{CO}_{2}$ atmospheric conditions for 24 hours and washed three times with PBS solution and a $\mathrm{pH}$ of 7.4 to remove the excess iron $[28,29]$. Solutions of GTE $(0-100 \mathrm{mg} / \mathrm{dl})$, EGCG $(0-200 \mu \mathrm{M})$, DFP $(0-200 \mu \mathrm{M})$, DFO $(0-200$ $\mu \mathrm{M})$, GTE $(0-100 \mathrm{mg} / \mathrm{dl})$ with $25 \mu \mathrm{M}$ DFP and EGCG $(0-200 \mu \mathrm{M})$ with $25 \mu \mathrm{M}$ DFP were freshly prepared in $50 \mathrm{mM}$ HEPES buffer at a $\mathrm{pH}$ of 7.2 and then filtered through a membrane (cellulose type $0.22 \mu \mathrm{m}$ ). The cells were incubated with the GTE, EGCG, DFP, DFO, GTE plus DFP and EGCG plus DFP solutions at $37^{\circ} \mathrm{C}$ for 6 , 12 and $24 \mathrm{~h}$ [30]. The treated cells were washed three times with the culture medium and labeled with calcein-AM solution (50 $\mu \mathrm{M}$ in DMSO). Fluorescent intensity (FI), which was inversely proportional to the analyzed amount of LIP, was measured with a 96-well plate reader spectrofluorometer (absorption/excitation wavelengths $485 \mathrm{~nm} / 530 \mathrm{~nm}$ ) [5]. Viability of studied cells was greater than $80 \%$ and was not changed during the assay.

\subsection{Reduction of ROS Levels of Cultured Hepatocytes}

DCFH-DA can simply diffuse into the cells and be hydrolyzed by esterase in viable cells to produce $2^{\prime}, 7^{\prime}$-dichlorofluorescein (DCFH), which will be subsequently oxidized by existing ROS to 2',7'-dichlorofluorescein (DCF). An increase of a green fluorescent signal indicates increased intracellular oxidative stress. The heaptocytes were incubated with the compounds as above at $37^{\circ} \mathrm{C}$ for $0,6,12$ and $24 \mathrm{~h}$. The treated cells were washed three times with the culture medium, labeled with DCFHDA solution (10 $\mu \mathrm{M}$ in methanol) for $30 \mathrm{~min}$, and chal- lenged with $\mathrm{H}_{2} \mathrm{O}_{2}$ solution $(125 \mu \mathrm{M})$. FI was measured using the spectrofluorometric technique (excitation/emission wavelengths $485 \mathrm{~nm} / 530 \mathrm{~nm}$ ) [31].

\subsection{Effects of Mitochondrial Membrane Potentials of Cultured Hepatocytes}

A cationic probe dihydrorhodamine 123 (DHR123) is used to signal the loss of mitochondrial membrane potential which results in changes in the fluorescent intensity termed redistribution signals. Nonfluorescent DHR123 readily enters most of the cells in the mitochondrial matrix in response to mitochondrial membrane potential and can be oxidized by cellular ROS or redox system to the fluorescent R123 that accumulates in the mitochondrial membranes [32]. Briefly, the hepatocytes treated with the compound(s) as above were centrifuged at $1000 \mathrm{~g}, 4^{\circ} \mathrm{C}$ for $1 \mathrm{~min}$. The cell pellet was resuspended in $2 \mathrm{ml}$ of the medium containing $1.5 \mu \mathrm{M}$ DHR123 and then incubated under $5 \% \mathrm{CO}_{2}$ atmospheric conditions at $37^{\circ} \mathrm{C}$ for 10 $\min$. After incubation, the cells were separated by centrifugation at $1000 \mathrm{~g}, 4^{\circ} \mathrm{C}$ for $1 \mathrm{~min}$ and $\mathrm{FI}$ was measured using the spectrofluorometric technique $\left(\lambda_{\text {excitation }} / \lambda_{\text {emission }}\right.$ $490 \mathrm{~nm} / 520 \mathrm{~nm}$ ). The capacity of mitochondria to take up the R123 was calculated as the difference of FI between untreated cells (control) and treated cells.

\section{RESULTS AND DISCUSSION}

We have demonstrated that catechin derivatives like EGCG and ECG in the green tea extract exhibit antioxidative and iron-chelating properties that can relieve iron overload and oxidative stress in the plasma compartment and vital organs (e.g. spleen, liver and heat) of rats and b-thalassemia mice $[11,20,21,33]$. Our present study supports the evidence that the extract and EGCG are effective in significantly decreasing intracellular LIP levels in the cultured mouse hepatocytes (Figure 1) and HepG2 cells (Figure 2). Most importantly, the combined treatment of $25 \mathrm{mM}$ DFP with GTE (12.5 and $25 \mathrm{mg} / \mathrm{dl})$ and with EGCG (50 and $100 \mathrm{mM}$ ) significantly enhanced the removal of LIP in the HepG2 cells, but not in the primary mouse hepatocytes (Figure 3). DFO and DFP could not lower the levels of ROS in the two hepatocytes, whereas the extract and EGCG tended to reduce the ROS levels significantly in a concentration-dependent manner (Figures 4 and 5, respectively).

Nonetheless, the combined treatment of DFP with the extract and EGCG did not give any different results of the ROS and membrane potential levels when compared to the treatment with the extract or the EGCG alone (Figure 6). Interestingly, the crude extract and EGCG lowered the level of the hepatic mitochondrial membrane potentials (Table 1). 

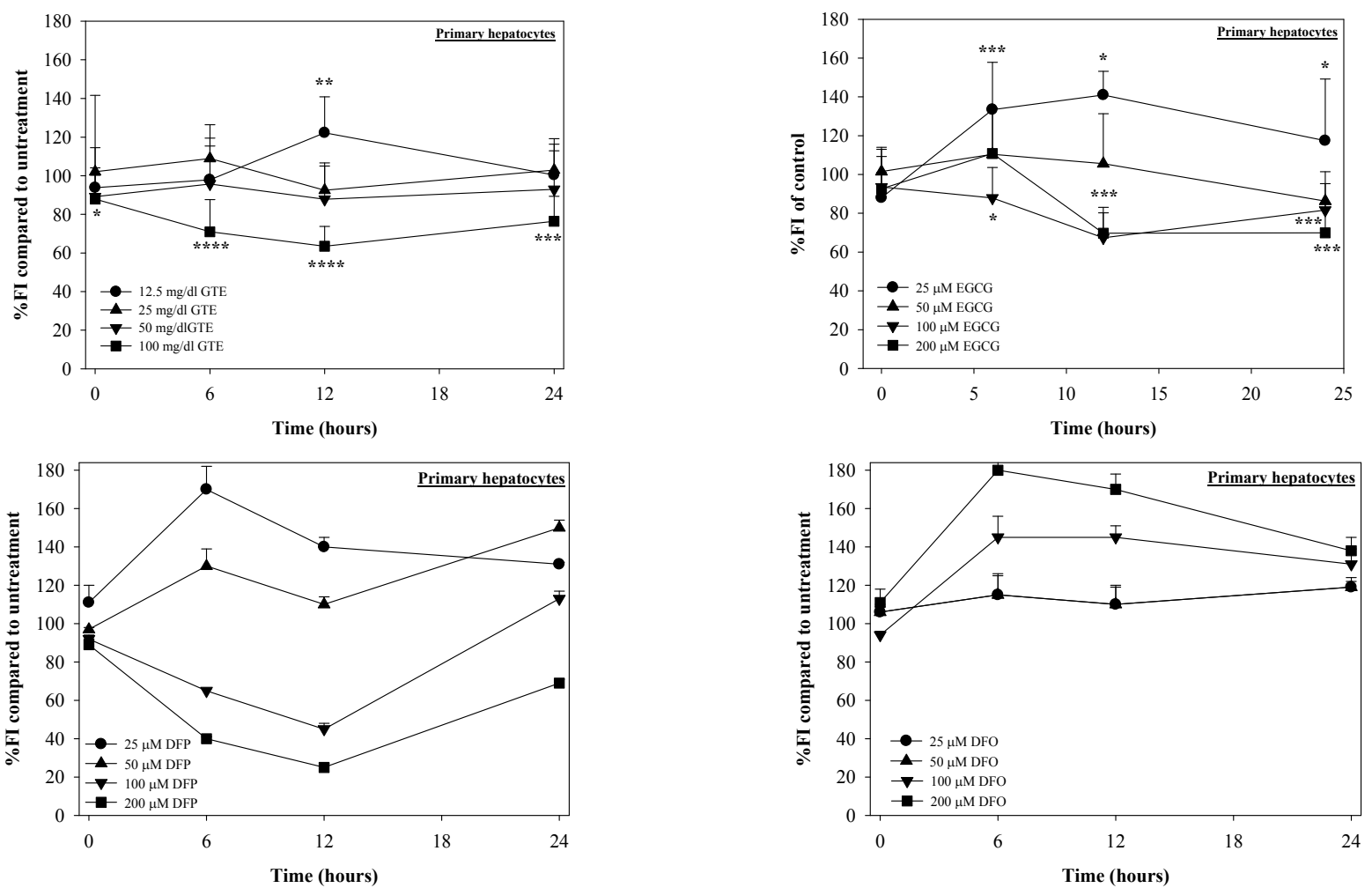

Figure 1. Treatments of EGCG, DFP and DFO $(25-200 \mu \mathrm{M})$, and GTE $(12.5-100 \mathrm{mg} / \mathrm{dl})$ on levels of LIP in mouse hepatocytes. Data were obtained from three independent triplicate experiments and shown as mean $\pm \mathrm{SD} .{ }^{*} p<0.05,{ }^{* *} p<$ $0.01,{ }^{* * *} p<0.001,{ }^{* * * *} p<0.0005$ compared to no treatment.
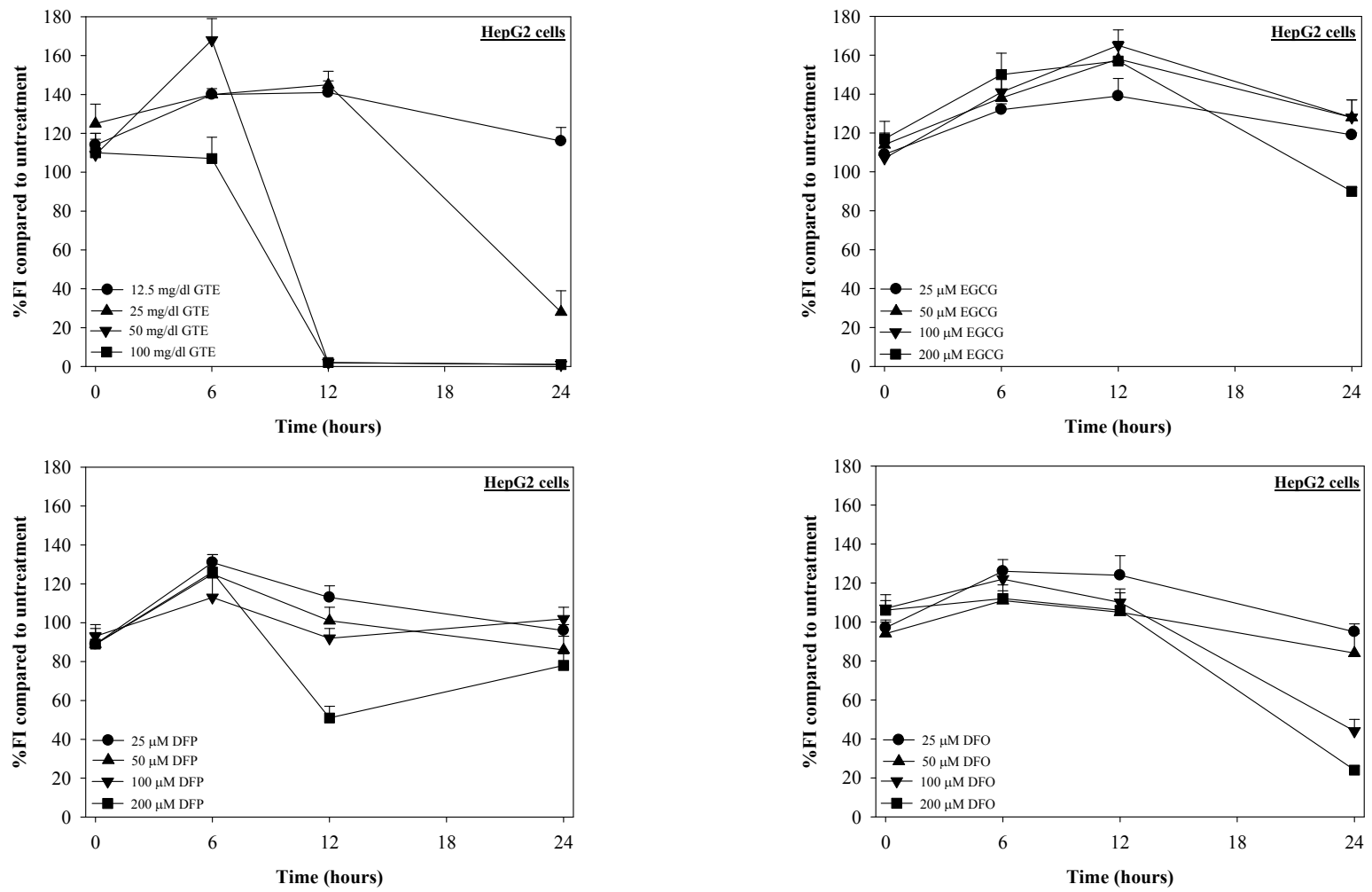

Figure 2. Treatments of EGCG, DFP and DFO $(25-200 \mu \mathrm{M})$, and GTE $(12.5-100 \mathrm{mg} / \mathrm{dl})$ on levels of LIP in HepG2 cells. Data were obtained from three independent triplicate experiments and shown as mean $\pm \mathrm{SD}$. 

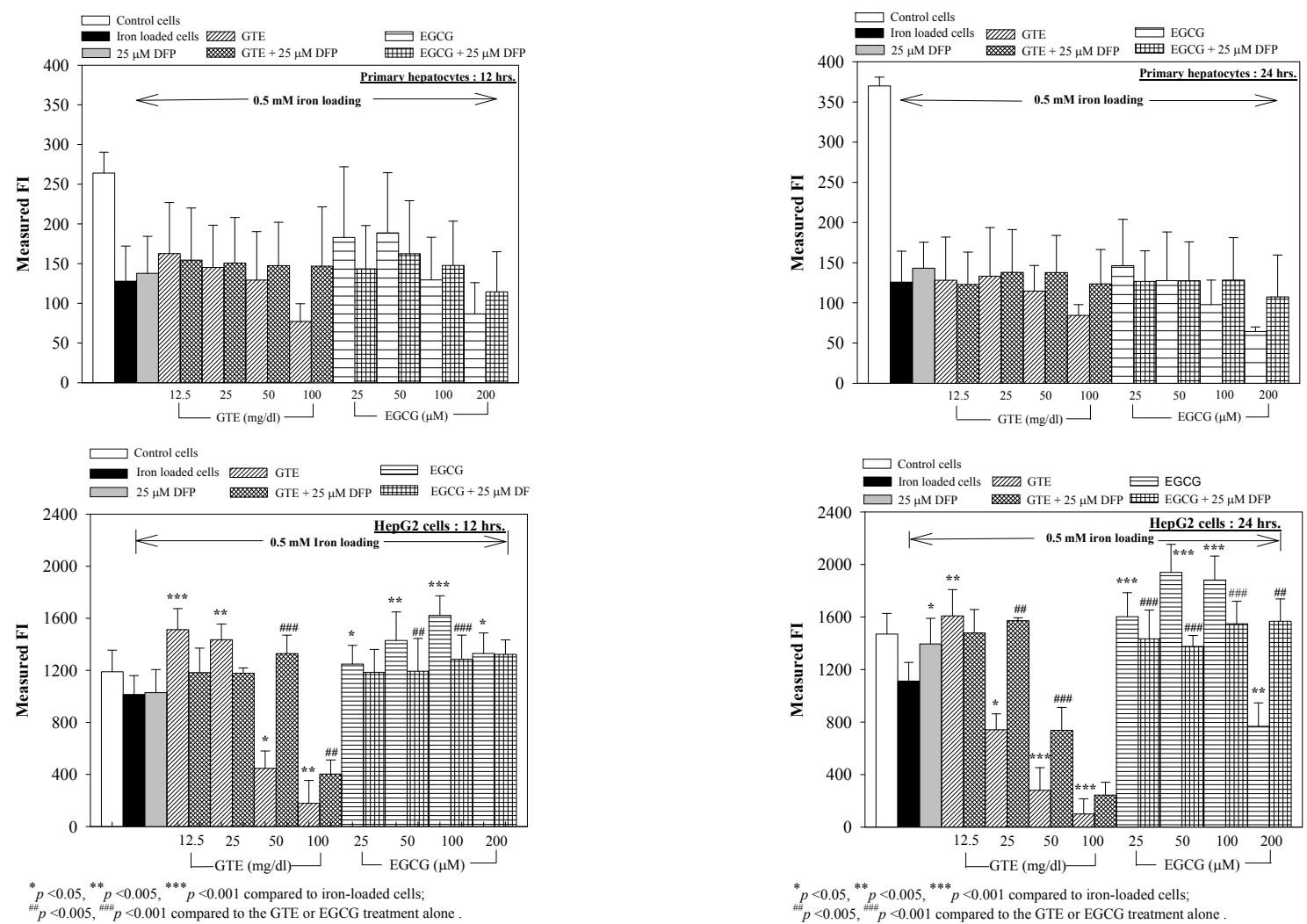

Figure 3. Combined treatments of $25 \mu \mathrm{M}$ DFP with GTE $(12.5-100 \mathrm{mg} / \mathrm{dl})$ and with EGCG $(25-200 \mu \mathrm{M})$ on levels of LIP in the hepatocytes. Data were obtained from three independent triplicate experiments and shown as mean $\pm \mathrm{SD}$.
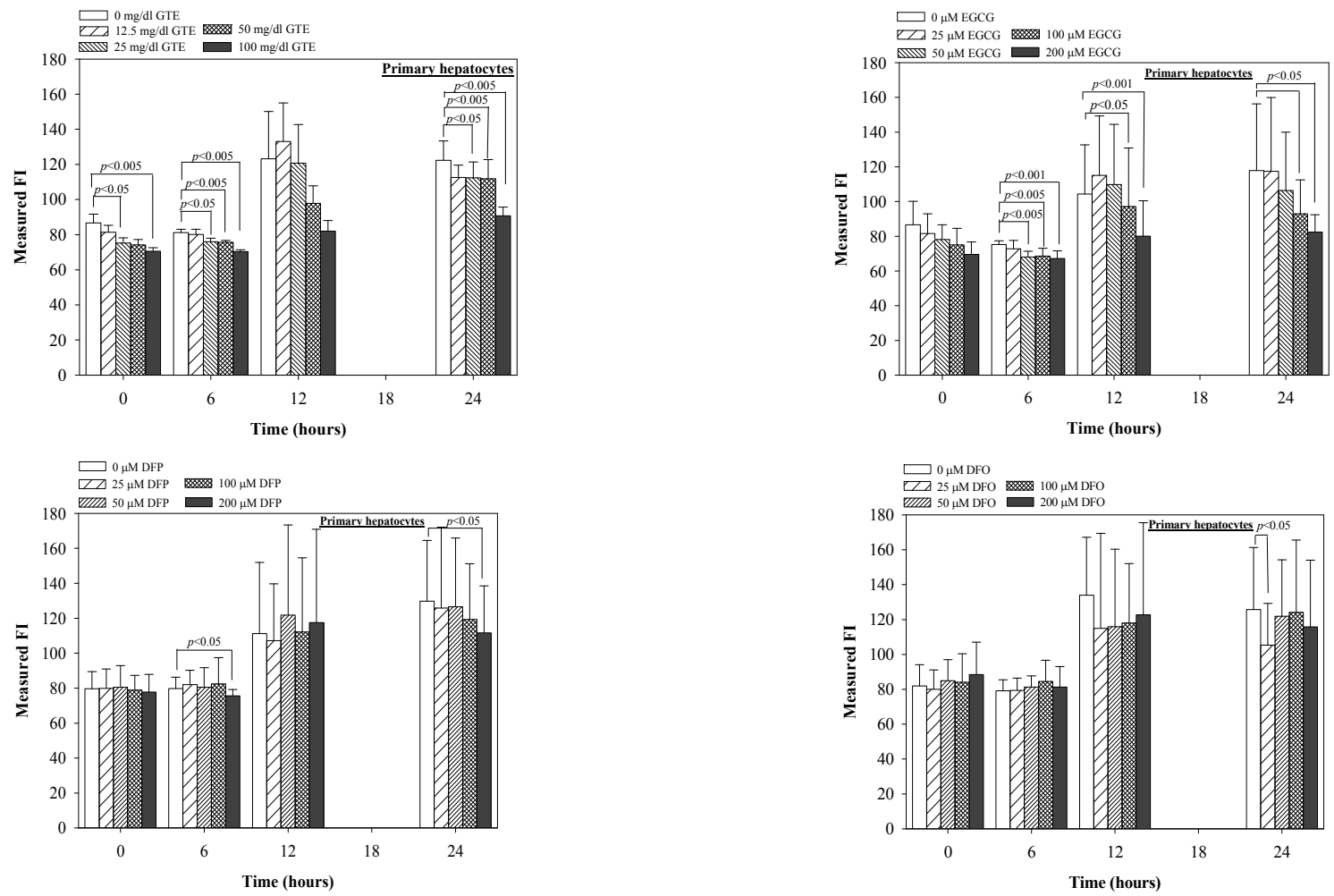

Figure 4. Treatments of EGCG, DFP and DFO $(25-200 \mu \mathrm{M})$, and GTE $(12.5-100 \mathrm{mg} / \mathrm{dl})$ on levels of ROS in mouse hepatocytes. Data were obtained from three independent triplicate experiments and shown as mean $\pm \mathrm{SD}$. 

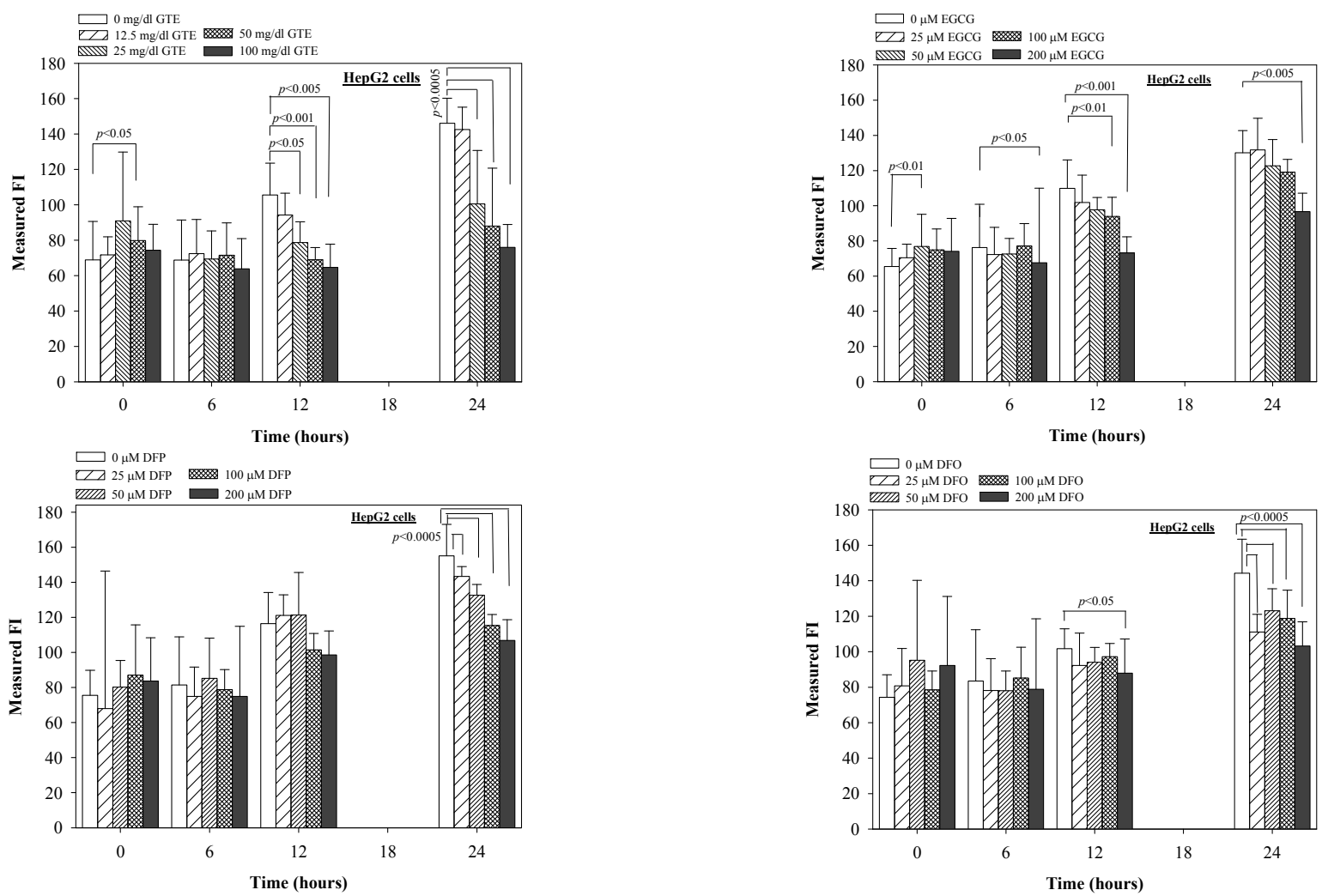

Figure 5. Treatments of EGCG, DFP and DFO $(25-200 \mu \mathrm{M})$, and GTE (12.5 - $100 \mathrm{mg} / \mathrm{dl})$ on levels of ROS in HepG2 cells. Data were obtained from three independent triplicate experiments and shown as mean $\pm \mathrm{SD}$.
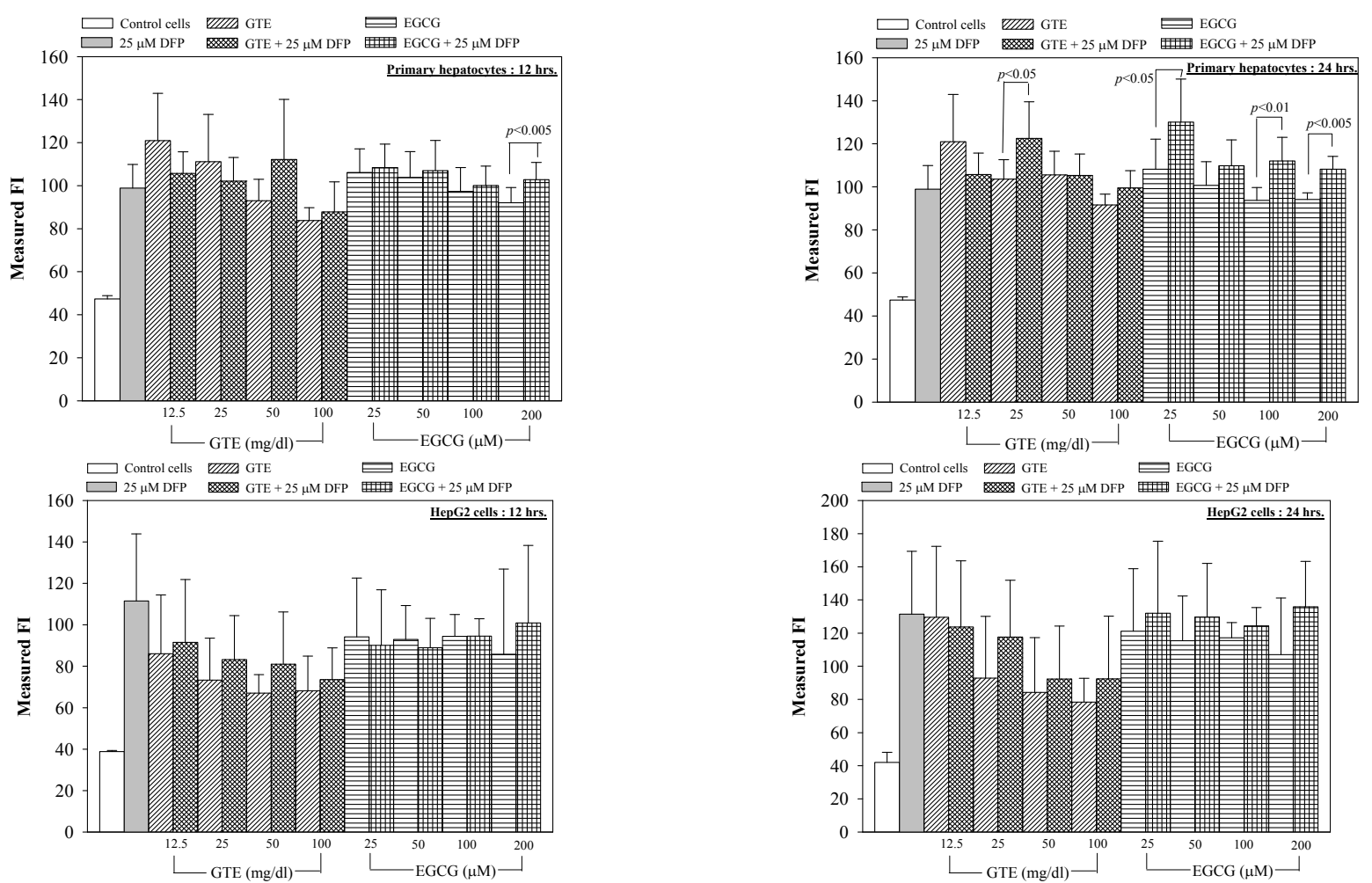

Figure 6. Combined treatments of $25 \mu \mathrm{M}$ DFP with GTE $(12.5-100 \mathrm{mg} / \mathrm{dl})$ and with EGCG $(25-200 \mu \mathrm{M})$ on levels of ROS in the hepatocytes. Data were obtained from three independent triplicate experiments and shown as mean $\pm \mathrm{SD}$. 
Table 1. Levels of mitochondrial membrane potential $\left(\Psi_{\mathrm{m}}\right)$ in the mouse hepatocytes treated with EGCG, DFP and DFO (25 - 200 $\mu \mathrm{M})$, GTE $(12.5-100 \mathrm{mg} / \mathrm{dl}), 25 \mu \mathrm{M}$ DFO plus EGCG $(25-200 \mu \mathrm{M})$, and $25 \mu \mathrm{M}$ DFP plus GTE $(12.5-100 \mathrm{mg} / \mathrm{dl})$. Data were obtained from three independent triplicate experiments and expressed as mean $\pm \mathrm{SD} .{ }^{*} p<0.05,{ }^{* *} p<0.005,{ }^{* * *} p<0.001$.

\begin{tabular}{|c|c|c|c|c|c|}
\hline \multirow{2}{*}{ Treatment } & & \multicolumn{4}{|c|}{ \%FI compared to no treatment } \\
\hline & & $\mathbf{O} \mathbf{h}$ & $6 \mathrm{~h}$ & $12 \mathrm{~h}$ & $24 \mathrm{~h}$ \\
\hline \multirow{5}{*}{ GTE (mg/dl) } & $\mathbf{0}$ & 100 & 100 & 100 & 100 \\
\hline & 12.5 & $94 \pm 9$ & $101 \pm 3$ & $93 \pm 9$ & $97 \pm 6$ \\
\hline & 25 & $104 \pm 17$ & $96 \pm 6$ & $96 \pm 6$ & $97 \pm 5^{*}$ \\
\hline & 50 & $102 \pm 14$ & $102 \pm 7$ & $113 \pm 11$ & $99 \pm 4$ \\
\hline & 100 & $104 \pm 13$ & $102 \pm 5$ & $99 \pm 14$ & $102 \pm 9$ \\
\hline \multirow{5}{*}{$\operatorname{EGCG}(\mu \mathrm{M})$} & $\mathbf{0}$ & 100 & 100 & 100 & 100 \\
\hline & 25 & $86 \pm 7^{* * *}$ & $94 \pm 11$ & $94 \pm 10$ & $87 \pm 15^{*}$ \\
\hline & 50 & $109 \pm 20$ & $98 \pm 3$ & $100 \pm 9$ & $105 \pm 20$ \\
\hline & 100 & $101 \pm 19^{*}$ & $99 \pm 4$ & $104 \pm 7$ & $99 \pm 11$ \\
\hline & 200 & $94 \pm 8^{* *}$ & $103 \pm 5$ & $95 \pm 8^{* *}$ & $104 \pm 10$ \\
\hline \multirow{5}{*}{$\mathrm{DFP}(\mu \mathrm{M})$} & $\mathbf{0}$ & 100 & 100 & 100 & 100 \\
\hline & 25 & $105 \pm 5^{* *}$ & $102 \pm 5$ & $108 \pm 9$ & $108 \pm 10$ \\
\hline & 50 & $107 \pm 9^{* * *}$ & $105 \pm 9$ & $98 \pm 4^{*}$ & $99 \pm 4$ \\
\hline & 100 & $89 \pm 10$ & $91 \pm 11$ & $91 \pm 9$ & $91 \pm 11$ \\
\hline & 200 & $103 \pm 8$ & $100 \pm 4$ & $110 \pm 11^{*}$ & $109 \pm 14$ \\
\hline \multirow{5}{*}{ DFO $(\mu \mathrm{M})$} & $\mathbf{0}$ & 100 & 100 & 100 & 100 \\
\hline & 25 & $107 \pm 9$ & $104 \pm 6^{*}$ & $108 \pm 13$ & $96 \pm 9$ \\
\hline & 50 & $102 \pm 5^{*}$ & $107 \pm 11^{*}$ & $106 \pm 10$ & $109 \pm 19$ \\
\hline & 100 & $97 \pm 8$ & $94 \pm 14$ & $94 \pm 6$ & $97 \pm 11$ \\
\hline & 200 & $102 \pm 7$ & $103 \pm 6$ & $107 \pm 10$ & $110 \pm 11$ \\
\hline \multirow{5}{*}{$25 \mu \mathrm{M} \mathrm{DFP}+\mathrm{GTE}(\mathrm{mg} / \mathrm{dl})^{\mathrm{s}}$} & $0^{\$}$ & 100 & 100 & 100 & 100 \\
\hline & 12.5 & $78 \pm 5^{* * *}$ & $91 \pm 9^{*}$ & $93 \pm 10$ & $92 \pm 13$ \\
\hline & 25 & $95 \pm 6^{* * *}$ & $102 \pm 5$ & $102 \pm 8$ & $98 \pm 8^{* *}$ \\
\hline & 50 & $112 \pm 14^{* * *}$ & $99 \pm 7$ & $102 \pm 7$ & $104 \pm 3$ \\
\hline & 100 & $90 \pm 13^{* *}$ & $101 \pm 5$ & $98 \pm 13^{*}$ & $99 \pm 3^{*}$ \\
\hline \multirow{5}{*}{$25 \mu \mathrm{M}$ DFP + EGCG $(\mu \mathrm{M})^{\S}$} & $0^{\S}$ & 100 & 100 & 100 & 100 \\
\hline & 25 & $93 \pm 4^{* *}$ & $93 \pm 10$ & $95 \pm 19$ & $94 \pm 11$ \\
\hline & 50 & $99 \pm 4^{* *}$ & $101 \pm 3$ & $94 \pm 8^{*}$ & $96 \pm 6^{*}$ \\
\hline & 100 & $100 \pm 8^{*}$ & $99 \pm 5$ & $100 \pm 7$ & $101 \pm 8$ \\
\hline & 200 & $98 \pm 4^{*}$ & $102 \pm 7$ & $97 \pm 6^{*}$ & $101 \pm 4$ \\
\hline
\end{tabular}

Like DFO and DFP, the substances behave as natural iron-chelating agents that can remove intracellular redox-active iron called LIP and scavenge produced ROS in the liver. The results imply that green tea catechins, especially EGCG would be hepatoprotective against iron overload-induced oxidative stress and inflammation.

Liver is the main organ for iron storage and metabolism, which can be affected by excessive redox iron and reactive oxidants. Drug regimens such as those that use an iron chelator or antioxidants are recommended for $\beta$-thalassemia patients with iron overload to relieve oxidative tissue damage and improve their quality of life [34, 35]. Moreover, the development of a cheap, orally effective iron chelator is of great importance [36]. Iron-overload diseases frequently develop hepatocellular carcinoma, which the pathogenesis might involve an oxidative process via the intermediate production of ROS. Examination of liver iron content is required for diagnosis of iron overload [37].
Phytochemicals possess outstanding antioxidant and free radical-scavenging properties, suggesting a possible protective role in man [38]. For instance, green tea is an excellent source of many antioxidative polyphenols and their beneficial effects can be applicable for treatments of $\beta$-thalassemia major patients. D-tagatose is an antioxidant and weak iron chelator which can remove redox-active iron and decrease oxidative stress in primary cultures of mouse hepatocytes [39]. Under iron overload, toxic irons such as non-transferrin bound iron (NTBI) and labile plasma iron (LPI) are transported in transferrin-saturated plasma and rapidly cleared by the liver. An in vitro study reported that cultured rat hepatocytes had a high capacity to take up the heterogeneous forms of NTBI by facilitated diffusion. HepG2 cells took up the iron for their rapid growth and proliferation faster than the hepatocytes of wild type mice did [40,41]. However, primary hepatocytes are still used as a cell culture model to identify mechanisms of hepatocellular damage, though 
there are some examples for compounds causing hepatic damage in vivo which could not be demonstrated in liver cells in vitro. Though GTE and EGCG potentially chelated redox-active iron and scavenged reactive oxidants in the liver cells with iron overload, a therapeutic dose of the compounds is important and needs optimizing to achieve effective chelation and minimal adverse effects. Gaboriau and colleagues showed that CP20 (or DFP) and CP411 efficiently protected cultured rat hepatocytes and hepatoma cells from a toxic effect of iron load [42]. One study demonstrated that DFO penetrated into the hepatocytes and chelated cytosolic LIP slowly, whereas DFP and DFX readily entered the cells and efficiently chelated the LIP [43]. Synthetic $\alpha$-ketohydroxypyridine chelator, such as DFP, was active in removing iron from the reticuloendothelial system and hepatocytes, and was superior to DFO [44].

To achieve a therapeutic approach, green tea catechins must readily penetrate into the cells and interact with intracellular reactive oxidants including redox-active iron and free radicals efficiently. Since HepG2 cells are highly metabolic human hepatoma cells and produce larger amounts of reactive oxidants, their free-radical scavenging activity seems to be more apparent than that of primary hepatocytes. EGCG was postulated to be a potent antioxidant and effectively afforded protection of rat primary hepatocytes from free radical-mediated diseases [45]. Mushroom (Phellinus linteus) protected primary rat hepatocytes from ferric nitrilotriacetate-induced oxidative damage and attenuated the cytotoxicity of other oxidants, possibly by increasing antioxidant (such as reduced glutathione) concentration and enhancing antioxidant enzyme activities (such as glutathione reductase, glutathione peroxidase, superoxide dismutase) [46,47]. In our observations, GTE and EGCG were toxic to HepG2 cells but not toxic to mouse hepatocytes when treated at high dose (data not shown). Our study using reducing powers-assayed MTT test also showed that the substances enhanced the viability of the cells (data not shown), probably due to a regeneration of the damaged livers that had been exposed to iron and free radicals.

Major hepatic toxicities of iron overload include damage to multiple cell types (hepatocytes, Kupfer cells, hepatic stellate cells) and to multiple subcellular organelles (mitochondria, lysosomes, and smooth endoplasmic reticulum) [48]. Evidence has shown that tea phenolic acids and catechins containing gallic acid moieties were toxic toward isolated rat hepatocytes, where the order of cytotoxicity was EGCG $>$ propyl gallate $>$ ECG $>$ gallic acid, EGC $>$ EC [18]. In our findings GTE, EGCG, DFP and DFO were toxic to the HepG2 cells, depending on the applied doses and the degree of the toxicity (GTE > DFO $>$ DFP $>$ EGCG), while the duration of chelation also influenced the cytotoxic effect (data not shown). A recent study has reported that a combination of the chloroform fraction from drinking tea (Zizyphus jujube) and GTE enhanced inhibition of HepG2 cell growth in G1 arrest phase, suggest a synergism in anticancer activity [19]. The extract of herbal tea (Ardisia compressa) had an antioxidant protective effect on rat hepatocytes when exposed to 1-NP, and was superior to EGCG anti-oxidation [49].

It was elucidated that iron suppressed the expression of chimeric human transferrin genes in the livers of transgenic mice and regulated the synthesis of endogenous transferrin in the HepG2 cells [50]. Iron was found to be cytotoxic in CYP 2E1-overexpressing HepG2 cells (E47 cells). In the development of toxicity by exposure of the hepatocytes to the tested compounds, the toxicity was prevented by antioxidants. Interestingly, Makino (Crossostephium chinensis L.) showed antioxidant, ironchelating and anti-proliferative activity in HepG2 cells [51]. Toxicity of increased ROS in the arachidonic acidenriched HepG2 cells can be prevented by antioxidants and DFO [52]. DFP and DFO have been shown to inhibit HepG2 cell proliferation in the S-phase of cell cycle [53]. The molar ratio of DFP to iron (at least 3:1) is optimal to inhibit ROS generation; nevertheless, lower concentrations of the DFP can potentiate oxidative DNA damage in iron-loaded HepG2 cells [54].

\section{CONCLUSION}

Green tea and EGCG effectively lowered levels of redox-active iron and ROS in primary hepatocyte and HepG2 cell cultures. EGCG also scavenged hepatic mitochondrial free radicals effectively and the benefit would prevent liver mitochondrial damage and apoptosis. Our findings imply the protective and therapeutic effects of green tea catechins on the liver with iron overload and oxidative stress. Prospectively, the merit adjunctive study of green tea products and DFP needs designing to prevent liver pathogenesis in b-thalassemia patients with iron overload in the near future.

\section{ACKNOWLEDGEMENTS}

This work was supported by the Thailand Research Fund (Mid-Career University) through Dr. Somdet Srichairatanakool (RMU5080074) and the Graduate School of Chiang Mai University through Miss Kanokwan Kulprachakarn. We thank the Thalassemia Research Center, Institute of Molecular Biosciences, Mahidol University for supplying mice (C57/BL6). The expert linguistic advice by Mr. Russell Kirk Hollis from the Department of English, Faculty of Humanities, Chiang Mai University is gratefully recognized.

\section{REFERENCES}

[1] Lesnefsky, E.J. (1994) Tissue iron overload and mecha- 
nisms of iron catalyzed oxidative injury. Advances in Experimental Medicine and Biology, 366, 129-146. doi:10.1007/978-1-4615-1833-4 10

[2] Britton, R.S., Ramm, G.A., Olynyk, J., Singh, R., O’Neill, R. and Bacon, B.R. (1994) Pathophysiology of iron toxicity. Advances in Experimental Medicine and Biology, 356, 239-253. doi:10.1007/978-1-4615-2554-7 26

[3] Emerit, J., Beaumont, C. and Trivin, F. (2001) Iron metabolism, free radicals, and oxidative injury. Biomedicine \& Pharmacotherapy, 55, 333-339. doi:10.1016/S0753-3322(01)00068-3

[4] Cederbaum, A.I. (2003) Iron and CYP2E1-dependent oxidative stress and toxicity. Alcohol, 30, 115-120. doi:10.1016/S0741-8329(03)00104-6

[5] Epsztejn, S., Kakhlon, O., Glickstein, H., Breuer, W. and Cabantchik, I. (1997) Fluorescence analysis of the labile iron pool of mammalian cells. Analytical Biochemistry, 248, 31-40. doi:10.1006/abio.1997.2126

[6] Gackowski, D., Kruszewsk, M., Banaszkiewicz, Z., Jawien, A. and Olinski, R. (2002) Lymphocyte labile iron pool, plasma iron, transferrin saturation and ferritin levels in colon cancer patients. Acta Biochimica Polonica, 49, 269272.

[7] Lipinski, P., Drapier, J.C., Oliveira, L., Retmanska, H., Sochanowicz, B. and Kruszewski, M. (2000) Intracellular iron status as a hallmark of mammalian cell susceptibility to oxidative stress: A study of L5178Y mouse lymphoma cell lines differentially sensitive to $\mathrm{H}(2) \mathrm{O}(2)$. Blood, 95, 2960-2966.

[8] Petrat, F., de Groot, H. and Rauen, U. (2001) Subcellular distribution of chelatable iron: A laser scanning microscopic study in isolated hepatocytes and liver endothelial cells. Biochemical Journal, 356, 61-69. doi:10.1042/0264-6021:3560061

[9] Corradini, E., Ferrara, F. and Pietrangelo, A. (2004) Iron and the liver. Pediatric Endocrinology Reviews, 2, 245248.

[10] Caro, A.A. and Cederbaum, A.I. (2004) Oxidative stress, toxicology, and pharmacology of CYP2E1. Annual Review of Pharmacology and Toxicology, 44, 27-42. doi:10.1146/annurev.pharmtox.44.101802.121704

[11] Srichairatanakool, S., Ounjaijean, S., Thephinlap, C., Khansuwan, U., Phisalpong, C. and Fucharoen, S. (2006) Iron-chelating and free-radical scavenging activities of microwave-processed green tea in iron overload. Hemoglobin, 30, 311-327. doi:10.1080/03630260600642666

[12] Khokhar, S., Venema, D., Hollman, P.C., Dekker, M. and Jongen, W. (1997) A RP-HPLC method for the determination of tea catechins. Cancer Letter, 114, 171-172. doi:10.1016/S0304-3835(97)04653-3

[13] Guo, Q., Zhao, B., Li, M., Shen, S. and Xin, W. (1996) Studies on protective mechanisms of four components of green tea polyphenols against lipid peroxidation in synaptosomes. Biochimca et Biophysica Acta, 1304, 210222. doi:10.1016/S0005-2760(96)00122-1

[14] Anghileri, LJ. and Thouvenot, P. (2000) Natural polyphenols-iron interaction: Its biological importance. Biological Trace Element Research, 73, 251-258. doi:10.1385/BTER:73:3:251
[15] Jimenez-Lopez, J.M. and Cederbaum, A.I. (2004) Green tea polyphenol epigallocatechin-3-gallate protects HepG2 cells against CYP2E1-dependent toxicity. Free Radical Biology and Medicine, 36, 359-370. doi:10.1016/j.freeradbiomed.2003.11.016

[16] Higuchi, A., Yonemitsu, K., Koreeda, A. and Tsunenari, S. (2003) Inhibitory activity of epigallocatechin gallate (EGCg) in paraquat-induced microsomal lipid peroxidation-A mechanism of protective effects of EGCg against paraquat toxicity. Toxicology, 183, 143-149. doi:10.1016/S0300-483X(02)00512-7

[17] Al-Bloushi, S., Safer, A.M., Afzal, M. and Mousa, S.A. (2009) Green tea modulates reserpine toxicity in animal models. Journal of Toxicological Sciences, 34, 77-87. doi: $10.2131 /$ its. 34.77

[18] Galati, G., Lin, A., Sultan, A.M. and O’Brien, P.J. (2006) Cellular and in vivo hepatotoxicity caused by green tea phenolic acids and catechins. Free Radical Biology and Medicine, 40, 570-580. doi:10.1016/j.freeradbiomed.2005.09.014

[19] Huang, X., Kojima-Yuasa, A., Xu, S., Norikura, T., Kennedy, D.O., Hasuma, T. and Matsui-Yuasa, I. (2008) Green tea extract enhances the selective cytotoxic activity of Zizyphus jujuba extracts in HepG2 cells. The American Journal of Chinese Medicine, 36, 729-744. doi:10.1142/S0192415X08006193

[20] Ounjaijean, S., Thephinlap, C., Khansuwan, U., Phisalapong, C., Fucharoen, S., Porter, J.B. and Srichairatanakool, S. (2008) Effect of green tea on iron status and oxidative stress in iron-loaded rats. Medicinal Chemistry, 4, 365-370. doi:10.2174/157340608784872316

[21] Saewong, T., Ounjaijean, S., Mundee, Y., Pattanapanyasat, K., Fucharoen, S., Porter, J.B. and Srichairatanakool, S. (2010) Effects of green tea on iron accumulation and oxidative stress in livers of iron-challenged thalassemic mice. Medicinal Chemistry, 6, 57-64. doi:10.2174/157340610791321479

[22] Tyson, C.A., LeValley, S.E., Chan, R., Hobbs, P.D. and Dawson, M.I. (1984) Biological evaluation of some ionophore-polymeric chelator combinations for reducing iron overload. Journal of Pharmacology and Experimental Therapeutics, 228, 676-681.

[23] Pippard, M.J., Jackson, M.J., Hoffman, K., Petrou, M. and Modell, C.B. (1986) Iron chelation using subcutaneous infusions of diethylene triamine penta-acetic acid (DTPA). Scandinavian Journal of Haematology, 36, 466472. doi:10.1111/j.1600-0609.1986.tb02282.x

[24] Wonke, B., Wright, C. and Hoffbrand, A.V. (1998) Combined therapy with deferiprone and desferrioxamine. British Journal of Haematology, 103, 361-364. doi:10.1046/j.1365-2141.1998.01002.x

[25] Balveer, K., Pyar, K. and Wonke, B. (2000) Combined oral and parenteral iron chelation in beta thalassaemia major. Medical Journal of Malaysia, 55, 493-497.

[26] Wu, D. and Cederbaum, A.I. (2008) Development and properties of HepG2 cells that constitutively express CYP2E1. Methods in Molecular Biology, 447, 137-150. doi:10.1007/978-1-59745-242-7 11

[27] Huang, Z.Z., Chen, C., Zeng, Z., Yang, H., Oh, J., Chen, 
L. and Lu, S.C. (2001) Mechanism and significance of increased glutathione level in human hepatocellular carcinoma and liver regeneration. The FASEB Journal, 15, 19-21.

[28] Trinder, D., Batey, R.G., Morgan, E.H. and Baker, E. (1990) Effect of cellular iron concentration on iron uptake by hepatocytes. American Journal of Physiology, 259, G611-G617.

[29] McAbee, D.D. and Ling, Y.Y. (1997) Iron-loading of cultured adult rat hepatocytes reversibly enhances lactoferrin binding and endocytosis. Journal of Cellular Physiology, 171, 75-86. doi:10.1002/(SICI)1097-4652(199704)171:1<75::AID-JC P9>3.0.CO;2-E

[30] Staubli, A. and Boelsterli, U.A. (1998) The labile iron pool in hepatocytes: Prooxidant-induced increase in free iron precedes oxidative cell injury. American Journal of Physiology, 274, G1031-1037.

[31] Perez-de-Arce, K., Foncea, R. and Leighton, F. (2005) Reactive oxygen species mediates homocysteine-induced mitochondrial biogenesis in human endothelial cells: Modulation by antioxidants. Biochemical and Biophysical Research Communications, 338, 1103-1109. doi:10.1016/j.bbrc.2005.10.053

[32] Petit, T., Izbicka, E., Lawrence, R.A., Nalin, C., Weitman, S.D. and Von Hoff, D.D. (1999) Activity of MKT 077, a rhodacyanine dye, against human tumor colony-forming units. Anticancer Drugs, 10, 309-315. doi:10.1097/00001813-199903000-00010

[33] Thephinlap, C., Ounjaijean, S., Khansuwan, U., Fucharoen, S., Porter, J.B. and Srichairatanakool, S. (2007) Epigallocatechin-3-gallate and epicatechin-3-gallate from green tea decrease plasma non-transferrin bound iron and erythrocyte oxidative stress. Medicinal Chemistry, 3, 289-296. doi:10.2174/157340607780620608

[34] Olivieri, N.F., Brittenham, G.M., Matsui, D., Berkovitch, M., Blendis, L.M., Cameron, R.G., McClelland, R.A., Liu, P.P., Templeton, D.M. and Koren, G. (1995) Iron-chelation therapy with oral deferipronein patients with thalassemia major. The New England Journal of Medicine, 332, 918-922. doi:10.1056/NEJM199504063321404

[35] Porter, J.B. (1997) A risk-benefit assessment of ironchelation therapy. Drug Safety, 17, 407-421. doi:10.2165/00002018-199717060-00006

[36] Porter, J.B. (2009) Optimizing iron chelation strategies in beta-thalassaemia major. Blood Reviews, 23, S3-S7. doi:10.1016/S0268-960X(09)70003-7

[37] Scott, B.C., Butler, J., Halliwell, B. and Aruoma, O.I. (1993) Evaluation of the antioxidant actions of ferulic acid and catechins. Free Radical Research Communications, 19, 241-253. doi:10.3109/10715769309056512

[38] Valberg, L.S., Ghent, C.N., Lloyd, D.A., Frei, J.V. and Chamberlain, M.J. (1978) Diagnostic efficacy of tests for the detection of iron overload in chronic liver disease. Canadian Medical Association Journal, 119, 229-236.

[39] Paterna, J.C., Boess, F., Staubli, A. and Boelsterli, U.A. (1998) Antioxidant and cytoprotective properties of Dtagatose in cultured murine hepatocytes. Toxicology and
Applied Pharmacology, 148, 117-125. doi:10.1006/taap.1997.8315

[40] Baker, E., Baker, S.M. and Morgan, E.H. (1998) Characterisation of non-transferrin-bound iron (ferric citrate) uptake by rat hepatocytes in culture. Biochimica et Biophysica Acta, 1380, 21-30. doi:10.1016/S0304-4165(97)00120-7

[41] Richardson, D.R., Chua, A.C. and Baker, E. (1999) Activation of an iron uptake mechanism from transferrin in hepatocytes by small-molecular-weight iron complexes: Implications for the pathogenesis of iron-overload disease. Journal of Laboratory and Clinical Medicine, 133, 144 151. doi:10.1016/S0022-2143(99)90007-0

[42] Gaboriau, F., Chantrel-Groussard, K. Rakba, N., Loyer, P., Pasdeloup, N., Hider, R.C., Brissot, P. and Lescoat, G. (2004) Iron mobilization, cytoprotection, and inhibition of cell proliferation in normal and transformed rat hepatocyte cultures by the hydroxypyridinone CP411, compared to CP20: A biological and physicochemical study. Biochemical Pharmacology, 67, 1479-1487. doi:10.1016/j.bcp.2003.12.019

[43] Glickstein, H., El, R.B., Shvartsman, M. and Cabantchik, Z.I. (2005) Intracellular labile iron pools as direct targets of iron chelators: A fluorescence study of chelator action in living cells. Blood, 106, 3242-3250. doi:10.1182/blood-2005-02-0460

[44] Brock, J.H., Liceaga, J., Arthur, H.M. and Kontoghiorghes, G.J. (1990) Effect of novel 1-alkyl-3-hydroxy-2methylpyrid-4-one chelators on uptake and release of iron from macrophages. American Journal of Hematology, 34, 21-25. doi:10.1002/ajh.2830340106

[45] Ramirez-Mares, M.V. and de Mejia, E.G. (2003) Comparative study of the antioxidant effect of ardisin and epigallocatechin gallate in rat hepatocytes exposed to benomyl and 1-nitropyrene. Food and Chemical Toxicology, 41, 1527-1535. doi:10.1016/S0278-6915(03)00169-8

[46] Ye, S.F., Hou, Z.Q. and Zhang, Q.Q. (2007) Protective effects of Phellinus linteus extract against iron overload-mediated oxidative stress in cultured rat hepatocytes. Phytotherapy Research, 21, 948-953. doi:10.1002/ptr.2182

[47] Meloche, B.A. and O'Brien, P.J. (1993) S-nitrosyl glutathione-mediated hepatocyte cytotoxicity. Xenobiotica, 23, 863-871. doi:10.3109/00498259309059414

[48] Bonkovsky, H.L. and Lambrecht, R.W. (2000) Iron-induced liver injury. Clinics in Liver Disease, 4, 409-429. doi:10.1016/S1089-3261(05)70116-1

[49] de Mejia, E.G. and Ramirez-Mares, M.V. (2002) Leaf extract from Ardisia compressa protects against 1-nitropyrene-induced cytotoxicity and its antioxidant defense disruption in cultured rat hepatocytes. Toxicology, 179, 151-162. doi:10.1016/S0300-483X(02)00242-1

[50] Barnum-Huckins, K. and Adrian, G.S. (2000) Iron regulation of transferrin synthesis in the human hepatoma cell line HepG2. Cell Biology International, 24, 71-77. doi:10.1006/cbir.1999.0456

[51] Chang, T.N., Huang, G.J., Ho, Y.L., Huang, S.S., Chang, H.Y. and Chang, Y.S. (2009) Antioxidant and antiprolif- 
erative activities of Crossostephium chinensis (L.) Makino. The American Journal of Chinese Medicine, 37, 797-814. doi:10.1142/S0192415X09007259

[52] Chen, Q., Galleano, M. and Cederbaum, A.I. (1998) Cytotoxicity and apoptosis produced by arachidonic acid in HepG2 cells overexpressing human cytochrome P-4502E1. Alcoholism: Clinical and Experimental Research, 22, 782784. doi:10.1111/j.1530-0277.1998.tb03868.x

[53] Chenoufi, N., Drenou, B., Loreal, O., Pigeon, C., Brissot,
P. and Lescoat, G. (1998) Antiproliferative effect of deferiprone on the Hep G2 cell line. Biochemical Pharmacology, 56, 431-437. doi:10.1016/S0006-2952(98)00071-9

[54] Cragg, L., Hebbel, R.P., Miller, W., Solovey, A., Selby, S. and Enright, H. (1998) The iron chelator L1 potentiates oxidative DNA damage in iron-loaded liver cells. Blood, 92, 632-638. 